\title{
Barriers, attitudes, confidence, and knowledge of nurses regarding metabolic health screening and intervention in people with mental illness: a pilot study from Uganda
}

\author{
Davy Vancampfort ${ }^{1,2}$, Andrew Watkins ${ }^{3,4}$, Philip B. Ward ${ }^{5,6}$, Michel Probst ${ }^{1}$, \\ Marc De Hert ${ }^{2}$, Tine Van Damme ${ }^{1}$, James Mugisha ${ }^{7,8}$
}

1. KU Leuven - University of Leuven, Department of Rehabilitation Sciences, Leuven, Belgium.

2. KU Leuven - University of Leuven, University Psychiatric Center KU Leuven, Kortenberg, Belgium.

3. Keeping the Body in Mind Program, The Bondi Centre, South Eastern Sydney Local Health District, Sydney, NSW, Australia.

4. Faculty of Health, University of Technology Sydney, Sydney, Australia.

5. School of Psychiatry, University of New South Wales, Sydney, Australia.

6. Schizophrenia Research Unit, Ingham Institute for Applied Medical Research, Liverpool, Australia.

7. Kyambogo University, Kampala, Uganda.

8. Butabika National Referral and Mental Health Hospital, Kampala, Uganda.

\begin{abstract}
Background: People with mental illness are at an increased risk for developing cardio-metabolic disorders. Routine screening following pharmacotherapy is however unacceptably low in sub-Saharan African countries with less than $1 \%$ adequately screened. It is unknown whether this is due to a lack of adequate competences.

Objectives: The aim of this pilot study was to assess the barriers, attitudes, confidence, and knowledge of nurses regarding metabolic health, prevention and treatment in Uganda.

Methods: Twenty-eight nurses (39\% female, $30.9 \pm 6.9$ years) completed the Metabolic - Barriers, Confidence, Attitudes and Knowledge Questionnaire and the physical activity prescription rate item of the Exercise in Mental Illness Questionnaire.

Results: More than 75\% had a positive attitude towards metabolic screening and intervention and more than $50 \%$ were confident in providing smoking cessation advice, and physical activity and nutritional counseling. However, $57 \%$ stated that their heavy workload prevented them from doing health screening and promotion activities. There was a negative correlation $(\varrho=-$ $0.54, \mathrm{P}=0.003$ ) between the frequency of physical activity prescription and the perception of the inability of patients to change. Conclusion: The present findings suggest that nurses are generally supportive of metabolic health screening and intervention but their high workload prevents them from implementing metabolic health interventions.
\end{abstract}

Keywords: Exercise, diet, metabolic syndrome, screening, smoking.

DOI: https://dx.doi.org/10.4314/ahs.v19i3.30

Cite as: Vancampfort D, Watkins A, Ward PB, Probst M, De Hert M, Van Damme T, Mugisha J. Barriers, attitudes, confidence, and knowledge of nurses regarding metabolic health screening and intervention in people with mental illness: a pilot study from Uganda. Afri Health Sci. 2019;19(3): 2546-2554. https:// dx.doi.org/10.4314/abs.v19i3.30

\section{Corresponding author: \\ Davy Vancampfort, \\ Tervuursevest 101 \\ 3001 Leuven, \\ Belgium \\ Tel.: +32 27580511 \\ Fax: +32 27599879 . \\ Email address: davy.vancampfort@kuleuven.be}

\section{Introduction}

Mental disorders are the leading cause of years lived with disability, accounting for almost $20 \%$ of all disability-associated burden in low-to-middle and high-income countries $^{1}$. The burden is estimated to increase further in the future $^{2}$ and will be increased by the greater risk for secondary cardio-metabolic co-morbidities impactingpeople with mental disorders ${ }^{3-5}$. Currently, people with severe mental illness (SMI) (i.e. schizophrenia spectrum, bipo- 
lar disorder, major depressive disorder) die worldwide on average 14.5 years earlier, and the mortality gap in sub-Saharan African (SSA) countries is larger (27.7 years) than elsewhere in the world ${ }^{6}$. One of the reasons might be that in most SSA countries less than one percent of the health budget is dedicated to integrated physical and mental health care ${ }^{7,8}$. As a result, mental health services are poorly resourced, in particular with regards to any physical health concerns, and treatment rates for people with mental disorders remain low, with treatment gaps over ninety percent ${ }^{9}$.

Pharmacotherapy is the mainstay of therapy programs for people with mental disorders in SSA ${ }^{10}$, but psychotropic medications lead to increased risk of cardio-metabolic disease $\mathrm{e}^{11,12}$. The metabolic risk associated with psychotropic medication has led to the development of several international treatment guidelines for routine metabolic screening and monitoring ${ }^{13,14}$. The extent and frequency of screening is debatable, but there is global consensus that baseline metabolic screening should form part of standard care for all patients with a regular prescription of any psychotropic medication ${ }^{15}$. However, a previous review demonstrated that routine screening following pharmacotherapy is unacceptably low in SSA countries with less than one percent adequately screened for all modifiable metabolic syndrome risk factors at baseline ${ }^{16}$. This is understandable given limited resources (including human resources) in many mental health centres.

A mental health system reform with a focus on a more holistic care is therefore urgently needed and should be operationalized ${ }^{17}$. Mental health nurses are well positioned to play a key role in providing holistic care for people who experience mental illness ${ }^{18,19}$ and play an essential role as service gatekeepers. Although mental health nurses have traditionally focused on addressing mental illness symptomatology, and the physical health care needs of their patients were often seen as of lower priority ${ }^{20}$, mental health nurses in Western settings today acknowledge that they have a substantial role in addressing physical health needs ${ }^{21}$. Data on barriers, knowledge and attitudes of nurses in low resourced mental health settings in lowto-middle income countries are however lacking. It is also not clear whether nurses working in mental health settings in these countries have the skills or knowledge to identify and manage the metabolic complications experienced by service users. Such information might assist in identifying topics for specific training in this area. There is evidence from high-income countries that even brief training can lead to improvements in rate of metabolic monitoring in inpatient settings ${ }^{21}$.

Therefore, the aim of the current study was to assess the barriers, attitudes, confidence, and knowledge of nurses regarding metabolic health, prevention and treatment in Uganda. A secondary aim was to explore associations of perceived barriers and the confidence to prescribe physical activity as an intervention with the reported physical activity prescription rate in a resource-poor context such as Uganda.

\section{Methods \\ Design}

This is a cross-sectional study.

\section{Setting and protocol}

The entire nursing staff in three adult inpatient mental health facilities of Butabika Hospital, Kampala, Uganda, were invited to participate. These three wards were purposely selected as they are some of the busiest in the hospital. Combined, the facilities can accommodate 130 inpatients, although more than 200 patients are often treated and 32 nurses are employed to care for patients in these wards. The entire nursing staff was provided with an information sheet outlining the purpose of the study. Survey completion was facilitated by reminding the nurses after two weeks to participate, and this through personal contact or via a telephone call. No incentive for completion of the survey was offered. Participation was anonymous and informed consent was assumed on completion and return of the survey. Data were collected from November to December, 2017. Ethical clearance for the study was received from the Butabika Hospital Research Committee.

\section{Barriers, confidence, attitudes and knowledge re- garding metabolic health screening and intervention} The Metabolic - Barriers, Confidence, Attitudes and Knowledge Questionnaire (M-BACK ${ }^{22}$ assesses participants' knowledge, confidence, attitudes and practice barriers of metabolic health screening, prevention and treatment. The questionnaire uses a five-point Likert-style scale from 'Strongly Disagree' to 'Strongly Agree' and includes four domains. Previous research22 indicated that the M-BACK is a reliable measure of the key elements of practitioner perceptions of barriers, and their knowledge, attitudes, and confidence regarding metabolic monitoring in people with mental illness. 


\section{Domain 1: Barriers}

Items one through four address barriers to metabolic screening and intervention, including, workload, consumer interest, conflict with mental health goals and inability to change. These questions are negatively posed with the scoring reversed. Possible scores for the barriers domain range from $4-20$.

\section{Domain 2: Attitudes}

Items five through eight investigate attitudes, including towards metabolic monitoring, the provision of smoking cessation advice, physical activity and nutritional intake. Possible scores for the attitudes domain range from $4-$ 20.

\section{Domain 3: Confidence}

Items nine through 12 assess the confidence of respondents in providing interventions to prevent or treat metabolic syndrome including smoking cessation, physical activity and nutritional interventions. Possible scores for the confidence domain range from 4-20.

\section{Domain 4: Knowledge}

Items 13 through 16 assess knowledge of metabolic syndrome, screening, interpreting pathology reports and understanding of the metabolic side effects of neuroleptic medication. Possible scores for the knowledge domain range from 4-16.

\section{Physical activity prescription behavior}

Physical activity prescription practices were determined using the question from the Exercise in Mental Illness Questionnaire - Health Professionals Version (EMIQHP) for which content validity and test-retest reliability was previously established ${ }^{23}$ : e.g., "Do you prescribe physical activity to people with a mental illness?" with four response options of: "Never", "Occasionally", "Most of the time" and "Always".

\section{Statistical analysis}

Participant demographics, responses to statements re- garding participants' knowledge, confidence, attitudes and practice barriers of metabolic health and frequency of exercise prescription are reported using descriptive statistics (mean $\pm \mathrm{SD}$, frequencies). In accordance with previous studies on knowledge, confidence, attitudes and practice barriers regarding a healthy lifestyle ${ }^{23,24}$, responses to statements were collapsed to three categories; "Agree", "Neutral", and "Disagree". Since the Likert scale responses are not assumed to be on an equal interval scale, the responses "Strongly agree" and "Agree" were collapsed to "Agree". Based on rating scale optimization, collapsing the positive responses ("Strongly agree" and "Agree") into one category is logical and does not create an artificial new category. Similarly, combining negative responses ("Strongly disagree" and "Disagree") demonstrates the strength of these responses, compared to neutral and positive responses ${ }^{25}$. The relationship between frequency of physical activity prescription ("Always" versus "Most of the time" versus "Occasionally" versus "Never") and the scores for the practice barriers for metabolic health screening and intervention and the physical activity confidence item were examined using Spearman's rho correlations. Correlation coefficients were interpreted according to earlier recommendations (26) where $0.00-0.30$ is a negligible correlation; $0.30-0.50$ is a low positive correlation; $0.50-0.70$ is a moderate positivecorrelation; $0.70-0.90$ is a high positive correlation and $0.90-1.00$ is a very high positive correlation. Conversely, correlation coefficients between -1.0 and zero are interpreted as negative correlations. Based on a $10 \%$ error margin, a confidence level of $95 \%$, a population size of 38 and a response distribution of $50 \%$, a minimum sample size of 28 was required. Data analysis was performed using SPSS 24.0.

\section{Results \\ Participants}

Twenty-eight nurses (88\% of the potential candidates), including 10 nurses without and 18 nurses with a specialist mental health nursing qualification, completed the questionnaires. The characteristics of respondents are shown in Table 1. 
Table 1. Demographic characteristics of respondents $(n=28)$

\begin{tabular}{lcc}
\hline Characteristic & Mean \pm SD & Range \\
\hline Age (years) & $30.9 \pm 6.9$ & $22-48$ \\
Years in profession & $7.0 \pm 7.4$ & $<1-34$ \\
\hline & Number of respondents & $\begin{array}{c}\text { Proportion of } \\
\text { respondents }\end{array}$ \\
\hline Gender (male) & 17 & $61 \%$ \\
Marital status (married) & 19 & $68 \%$ \\
Full time employment & 24 & $86 \%$ \\
(yes) & & \\
\hline
\end{tabular}

Barriers regarding mental health screening and intervention

Responses to statements regarding practice barriers are shown in Table 2. When collapsed to categories of
'Agree', 'Neutral', and 'Disagree', more than half of the respondents agreed that "their workload prevented them from doing any health promotion activities with patients $(16 / 28,57 \%)$.

Table 2. Level of agreement $[n(\%)]$ with statements regarding barriers to metabolic screening and intervention.

\begin{tabular}{|c|c|c|c|c|c|}
\hline & Strongly disagree & Disagree & $\begin{array}{l}\text { Neither } \\
\text { disagree / } \\
\text { agree }\end{array}$ & Agree & Strongly agree \\
\hline $\begin{array}{l}\text { My workload } \\
\text { prevents me doing } \\
\text { any health } \\
\text { promotion } \\
\text { activities with } \\
\text { clients. }\end{array}$ & $0(0 \%)$ & $9(32 \%)$ & $3(11 \%)$ & $12(43 \%)$ & $4(14 \%)$ \\
\hline $\begin{array}{l}\text { Consumers with a } \\
\text { serious mental } \\
\text { illness are not } \\
\text { interested in } \\
\text { improving their } \\
\text { physical health. }\end{array}$ & $8(29 \%)$ & $10(36 \%)$ & $1(4 \%)$ & $5(18 \%)$ & $4(14 \%)$ \\
\hline $\begin{array}{l}\text { Informing clients } \\
\text { about the possible } \\
\text { effects of medications } \\
\text { may have on their } \\
\text { mental health will } \\
\text { increase non- } \\
\text { adherence. }\end{array}$ & $4(14 \%)$ & $8(29 \%)$ & $6(21 \%)$ & $8(29 \%)$ & $2(7 \%)$ \\
\hline $\begin{array}{l}\text { Screening for metabolic } \\
\text { syndrome and physical } \\
\text { health interventions are } \\
\text { pointless as poor physical } \\
\text { health outcomes are } \\
\text { unavoidable. }\end{array}$ & $8(29 \%)$ & $10(36 \%)$ & $4(14 \%)$ & $5(18 \%)$ & $1(4 \%)$ \\
\hline
\end{tabular}

Attitudes regarding mental health screening and intervention

The agreement with statements expressed by the nurses regarding their attitude towards metabolic health screening and intervention is shown in Table 3. In a manner similar to the responses to statements regarding barriers, scale optimization was performed to result in three cate- gories. When collapsed to categories of "Agree", "Neutral", and "Disagree", more than half of the respondents agreed with the all the statements, i.e. the importance of metabolic screening $(23 / 28 ; 82 \%)$, advice on smoking cessation $(25 / 28 ; 89 \%)$, encouraging physical activity $(26 / 28 ; 93 \%)$ and advice on nutritional intake (26/28; $93 \%)$. 
Table 3. Level of agreement $[n(\%)]$ with statements regarding attitudes to metabolic screening and intervention.

\begin{tabular}{|c|c|c|c|c|c|}
\hline & Strongly disagree & Disagree & Neither disagree / agree & Agree & $\begin{array}{c}\text { Strongly } \\
\text { agree }\end{array}$ \\
\hline $\begin{array}{l}\text { Metabolic health screening is an } \\
\text { important part of my role as a mental } \\
\text { health clinician. }\end{array}$ & $0(0 \%)$ & $2(7 \%)$ & $3(11 \%)$ & $15(54 \%)$ & $8(29 \%)$ \\
\hline $\begin{array}{l}\text { Giving smoking cessation advice is an } \\
\text { important part of my role as a mental } \\
\text { health clinician. }\end{array}$ & $1(4 \%)$ & $2(7 \%)$ & $0(0 \%)$ & $11(39 \%)$ & $14(50 \%)$ \\
\hline $\begin{array}{l}\text { Discussing nutritional intake is an } \\
\text { important part of my role as a mental } \\
\text { health clinician. }\end{array}$ & $0(0 \%)$ & $1(4 \%)$ & $1(4 \%)$ & $12(43 \%)$ & $14(50 \%)$ \\
\hline
\end{tabular}

Confidence regarding mental health screening and intervention

When collapsed to categories of "Agree", "Neutral", and

"Disagree", more than half of the respondents agreed that they feel confident to provide smoking cessation $(19 / 28$; 68\%), physical activity $(18 / 28 ; 64 \%)$ and nutritional interventions $(20 / 28 ; 71 \%)$. Only $36 \%(10 / 28)$ of the respondents agreed that they feel confident to screen (See Table 4).

Table 4. Level of agreement $[n(\%)]$ with statements regarding confidence to screen and intervene

\begin{tabular}{|c|c|c|c|c|c|}
\hline & $\begin{array}{l}\text { Strongly } \\
\text { disagree }\end{array}$ & Disagree & Neither disagree / agree & Agree & Strongly agree \\
\hline $\begin{array}{l}\text { I am confident in my ability to } \\
\text { screen for metabolic syndrome. }\end{array}$ & $0(0 \%)$ & $6(21 \%)$ & $12(43 \%)$ & $9(32 \%)$ & $1(4 \%)$ \\
\hline $\begin{array}{l}\text { I am confident in providing } \\
\text { smoking cessation advice to } \\
\text { consumers }\end{array}$ & $0(0 \%)$ & $1(4 \%)$ & $8(29 \%)$ & $12(43 \%)$ & $7(25 \%)$ \\
\hline $\begin{array}{l}\text { I am confident in prescribing } \\
\text { exercise interventions to prevent } \\
\text { / treat metabolic syndrome. }\end{array}$ & $0(0 \%)$ & $3(11 \%)$ & $7(25 \%)$ & $13(46 \%)$ & $5(18 \%)$ \\
\hline $\begin{array}{l}\text { I am confident in using dietary } \\
\text { interventions to prevent / treat } \\
\text { metabolic syndrome in } \\
\text { consumers. }\end{array}$ & $0(0 \%)$ & $4(14 \%)$ & $4(14 \%)$ & $16(57 \%)$ & $4(14 \%)$ \\
\hline
\end{tabular}

\section{Knowledge regarding mental health screening and intervention}

As shown in Table 5, exactly half of the respondents agreed they had sufficient knowledge as to what constitutes the metabolic syndrome $(14 / 28 ; 50 \%)$ and how to screen for it $(14 / 28 ; 50 \%)$, while more than half of the respondents agreed that they know how to read pathology reports of lipid and glucose results $(17 / 28 ; 61 \%)$, and they acknowledged that they undersood the metabolic side-effect profiles of different neuroleptic medications $(20 / 28 ; 71 \%)$. 
Table 5. Level of agreement $[n(\%)]$ with statements regarding knowledge about metabolic health issues and screening.

\begin{tabular}{|c|c|c|c|c|c|}
\hline & Strongly disagree & Disagree & Neither disagree / agree & Agree & Strongly agree \\
\hline $\begin{array}{l}\text { I have a good knowledge of } \\
\text { metabolic syndrome. }\end{array}$ & $0(0 \%)$ & $7(25 \%)$ & $7(25 \%)$ & $10(36 \%)$ & $4(14 \%)$ \\
\hline $\begin{array}{l}\text { I understand how to screen for } \\
\text { metabolic syndrome. }\end{array}$ & $0(0 \%)$ & $6(21 \%)$ & $8(29 \%)$ & $10(36 \%)$ & $4(14 \%)$ \\
\hline $\begin{array}{l}\text { I understand how to read } \\
\text { pathology reports for lipids and } \\
\text { glucose results. }\end{array}$ & $1(4 \%)$ & $7(25 \%)$ & $3(11 \%)$ & $15(54 \%)$ & $2(7 \%)$ \\
\hline $\begin{array}{l}\text { I understand the metabolic } \\
\text { side-effect profiles of different } \\
\text { neuroleptic medication. }\end{array}$ & $1(4 \%)$ & $2(7 \%)$ & $5(18 \%)$ & $10(36 \%)$ & $10(36 \%)$ \\
\hline
\end{tabular}

\section{Frequency of physical activity prescription}

Three respondents (11\%) reported "always" prescribing physical activity, $3(11 \%)$ reported prescribing physical activity "most of the time", 21 (75\%) reported prescribing physical activity "occasionally" to their patients and one (4\%) reported "never" prescribing physical activity.

\section{Correlates between the frequency of physical activi- ty prescription and the barrier scores}

There was no significant correlation between the frequency of physical activity prescription and the scores for the workload barrier $(\varrho=-0.31, \mathrm{P}=0.11)$, consumer interest barrier $(\varrho=-0.30, \mathrm{P}=0.12)$, conflict with mental health goals barrier $(\varrho=0.04, \mathrm{P}=0.82)$, and the confidence to prescribe physical activity $(\varrho=0.02, \mathrm{P}=0.95)$, but there was a moderate negative correlation with the perception of the inability of patients to change ( $\varrho=-0.54, \mathrm{P}=0.003)$.

\section{Discussion}

\section{General findings}

The current study is the first to assess barriers, attitudes, confidence, and knowledge of nurses regarding metabolic health, prevention and treatment in a low-income country. Our data suggest that nurses working in an inpatient service in Uganda have a good basic knowledge of the metabolic health risks patients with mental illness are confronted with. More than half of the respondents indicated that that they knew how to read lipid and glucose results. More than three quarters of the respondents also have a positive attitude towards metabolic screening and intervention and more than half were confident in providing smoking cessation advice, and physical activity and nutritional counseling. The high level of awareness about the metabolic health risks, and the good basic knowledge about and confidence in metabolic screening, prevention and treatment, in the majority of the nurses is likely due to continued medical education (CME) programs. Since Butabika hospital is the only national mental referral hospital, many of its staff are exposed to information related to lifestyle counseling, owing to the fact that the hospital runs more educational sessions than at other settings, from both local resources and donors. The positive attitude towards holistic care and the good basic knowledge of Ugandan nurses are however not new and have been reported in other health programs delivered by hospitals in Uganda ${ }^{27}$. The Ministry of Health needs to consolidate this human capital. However, our study also indicates that not all nurses have benefited yet from te available educational programs and ongoing efforts are needed. Our data suggest that those who believe that physical health interventions are pointless as poor physical health outcomes are unavoidable (22\% agree while $14 \%$ are neutral related to this statement), will also in practice less frequently prescribe physical activity. Next to this, a screening of the 100 most recent medical files ofthe Butabika Hospital, Kampala, Uganda (data not presented) demonstrated that in none of the patients were all metabolic syndrome components screened for and reported. Therefore, it seems that the positive attitude and good basic knowledge of the nurses have not yet translated into good clinical practice. Continuing the CME program to reach all nurses working in mental health, has the ability to improve the attitudes, confidence and knowledge of nurses in delivering metabolic screening and intervention. It is also important to test pre- and post effectiveness of such training through tools such as the EMIQ-HP and 
M-BACK in order to refine and improve this training in the future.

Another important observation in our study was that $57 \%$ of the respondents stated that their heavy workload prevented them from doing health screening and promotion activities with patients. It is important to note that other studies report institutional constraints for other health facilities in Uganda, such as treatment settings for malaria ${ }^{28}$ and $\mathrm{HIV}^{29}$, that include lack of human resources, infrastructure, and low monitoring rates. The major implication is that there is need for a systemic change in health delivery systems in Uganda ${ }^{30,31}$. The Ugandan Ministry of Health needs to consider such constraints through its general and mental health care plans. Training institutions in Uganda for medical cadres should follow suit in bridging some of these gaps, especially human resource gaps. Unfortunately, the mental health budget is less than one percent of the overall health care budget ${ }^{32}$ and therefore the current challenges are likely to persist unless more funding becomes available. An alternative would be to introduce and strengthen the integration of lifestyle counseling in the ongoing efforts to integrate mental health into primary health care levels. It is vital that community resource persons (e.g., village health teams) at the primary health care level are empowered to deliver lifestyle counseling to people with mental health problems. However, the staff at this level are also already overwhelmed by service demands.

\section{Limitations}

The present study should be considered in the light of some limitations. First, we did not obtain surveys from nurses working in rural mental health settings. Together with the small number of nurses participating (albeit $88 \%$ of the potential candidates completed the questionnaires), the generalizability of our findings remains to be confirmed. Second, we did not assess the reliability and validity of the M-BACK22 in the current setting and therefore data should be interpreted with caution.

\section{Conclusion}

The present findings suggest that the nurses who participated in this study are generally supportive of metabolic health screening and intervention. More than half are also confident in providing smoking cessation advice, and physical activity and nutritional counseling. However, the high workload prevents them from implementing metabolic health interventions. More human resources within the mental health system are needed. Policy endeavors are also needed to integrate mental health into primary health care. Further examination in larger cohorts, including nurses in rural settings, will progress our understanding of the delivery of metabolic screening, prevention and treatment for people with mental illness in low-resource settings.

\section{Acknowledgements}

The authors would like to thank the nurses of the Butabika National Referral and Mental Health Hospital who completed the questionnaires for the purpose of this study.

\section{Conflict of interest}

None to declare from all author.

\section{Funding}

This research was funded by Geestkracht VZW.

\section{Role of funding source}

The funding organization had no role in the research at any stage, nor influenced the decision to publish the article.

\section{References}

1. Whiteford HA, Degenhardt L, Rehm J, Baxter AJ, Ferrari AJ, Erskine HE, et al. Global burden of disease attributable to mental and substance use disorders: findings from the Global Burden of Disease Study 2010. The Lancet. 2013;382(9904):1575-86. doi: 10.1016/S01406736(13)61611-6.

2. Metrics \& Evaluation. The global burden of disease: generating evidence, guiding policy. Seattle, Washington, USA; 2013.

3. Vancampfort D, Stubbs B, Mitchell AJ, De Hert M, Wampers M, Ward PB, et al. Risk of metabolic syndrome and its components in people with schizophrenia and related psychotic disorders, bipolar disorder and major depressive disorder: a systematic review and meta-analysis. World Psychiatry. 2015;14(3):339-47. doi: 10.1002/ wps.20252.

4. Vancampfort D, Correll CU, Galling B, Probst M, De Hert M, Ward PB, et al. Diabetes mellitus in people with 
schizophrenia, bipolar disorder and major depressive disorder: a systematic review and large scale meta-analysis. World Psychiatry. 2016; 15(2):166-74. doi: 10.1002/ wps.20309.

5. Sorsdahl K, Sewpaul R, Evans M, Naidoo P, Myers B, Stein DJ. The association between psychological distress, alcohol use and physical non-communicable diseases in a nationally representative sample of South Africans. Journal of Health Psychology. 2016:1359105316642832. doi: $10.1177 / 1359105316642832$.

6. Hjorthøj C, Stürup AE, McGrath JJ, Nordentoft M. Years of potential life lost and life expectancy in schizophrenia: a systematic review and meta-analysis. The Lancet Psychiatry. 2017;4(4):295-301. doi: 10.1016/S22150366(17)30078-0.

7. Mugisha J. Towards understanding the dilemmas in prevention of mental illness in Uganda. The Edwin Mellen Press; 2016.

8. World Health Organization (2011). Mental Health Atlas 2011. Geneva: World Health Organization.

9. Lund C, Alem A, Schneider M, Hanlon C, Ahrens J, Bandawe $\mathrm{C}$, et al. Generating evidence to narrow the treatment gap for mental disorders in sub-Saharan Africa: rationale, overview and methods of AFFIRM. Epidemiology and Psychiatric Sciences. 2015;24(03):233-40. doi: 10.1017/S2045796015000281.

10. De Hert M, Detraux J, van Winkel R, Yu W, Correll CU. Metabolic and cardiovascular adverse effects associated with antipsychotic drugs. Nature Reviews Endocrinology. 2012;8(2):114-26. doi: 10.1038/nrendo.2011.156.

11. Correll C, Detraux J, De Lepeleire J, De Hert M. Effects of antipsychotics, antidepressants and mood stabilizers on risk for physical diseases in people with schizophrenia, depression and bipolar disorder. World Psychiatry. 2015;14(2):119-36. doi: 10.1002/wps.20204.

12. De Hert M, Vancampfort D, Correll C, Mercken V, Peuskens J, Sweers K, et al. Guidelines for screening and monitoring of cardiometabolic risk in schizophrenia: systematic evaluation. The British Journal of Psychiatry. 2011;199(2):99-105. doi: 10.1192/bjp.bp.110.084665.

13. De Hert M, Cohen D, Bobes J, Cetkovich-Bakmas M, Leucht S, Ndetei DM, et al. Physical illness in patients with severe mental disorders. II. Barriers to care, monitoring and treatment guidelines, plus recommendations at the system and individual level. World Psychiatry. 2011;10(2):138-51.
14. De Hert M, Correll CU, Bobes J, Cetkovich-Bakmas M, Cohen DAN, Asai I, et al. Physical illness in patients with severe mental disorders. I. Prevalence, impact of medications and disparities in health care. World Psychiatry. 2011;10(1):52-77.

15. Mugisha J, Hert MD, Stubbs B, Basangwa D, Vancampfort D. Physical health policies and metabolic screening in mental health care systems of Sub-Saharan African countries: a systematic review. International Journal of Mental Health Systems. 2017;11:31. doi: 10.1186/ s13033-017-0141-7.

16. Mugisha J, Abdulmalik J, Hanlon C, Petersen I, Lund C, Upadhaya N, et al. Health systems context (s) for integrating mental health into primary health care in six Emerald countries: a situation analysis. International Journal of Mental Health Systems. 2017;11(1):7. doi: 10.1186/s13033016-0114-2.

17. Gray R, Hardy S, Anderson KH. Physical health and severe mental illness: If we don't do something about it, who will? International Journal of Mental Health Nursing. 2009;18(5):299-300. doi: 10.1111/j.14470349.2009.00640.x

18. Happell B, Platania-Phung C, Scott D. Are nurses in mental health services providing physical health care for people with serious mental illness? An Australian perspective. Issues in Mental Health Nursing. 2013; 34: 198-207 PubMed. doi: 10.3109/01612840.2012.733907.

19. Happell B, Stanton R, Hoey W, Scott D. Cardiometabolic health nursing to improve health and primary care access in community mental health consumers: Protocol for a randomised controlled trial. International Journal of Nursing Studies. 2014; 51(2): 236-242. doi: 10.3109/01612840.2013.842619.

20. Robson D, Haddad M, Gray R, Gournay K. Mental health nursing and physical health care: A cross-sectional study of nurses' attitudes, practice, and perceived training needs for the physical health care of people with severe mental illness. International Journal of Mental Health Nursing. 2013;22(5):409-17. doi: 10.1111/j.14470349.2012.00883.x.

21. Rosenbaum S, Nijjar S, Watkins A, Garwood N, Sherrington $\mathrm{C}$, Tiedemann $\mathrm{A}$. Nurse-assessed metabolic monitoring: A file audit of risk factor prevalence and impact of an intervention to enhance measurement of waist circumference. International Journal of Mental Health Nursing. 2014;23(3):252-6. doi: 10.1111/inm.12057. 
22. Watkins A, Rosenbaum S, Ward PB, Patching J, Denney-Wilson E, Stein-Parbury J. The validity and reliability characteristics of the M-BACK Questionnaire to assess the barriers, attitudes, confidence and knowledge of mental health staff regarding metabolic health of mental health service users. Frontiers in Public Health. 2017;5:321. doi: 10.3389/fpubh.2017.00321

23. Stanton R, Happell B, Reaburn P. The development of a questionnaire to investigate the views of health professionals regarding exercise for the treatment of mental illness. Mental Health and Physical Activity. 2014;7(3):17782. doi: 10.1016/j.mhpa.2014.06.001.

24. Stanton R, Reaburn P, Happell B. Barriers to exercise prescription and participation in people with mental illness: the perspectives of nurses working in mental health. Journal of Psychiatric and Mental Health Nursing. 2015;22(6):440-8. doi: 10.1111/jpm.12205.

25. Royal, K. D., Ellis, A., Ensellen, A. \& Homan, A. (2010). Rating scale optimization in survey research: An application of the Rasch rating scale model. Journal of Applied Quantitative Methods, 5.

27. Mukaka MM. A guide to appropriate use of correlation coefficient in medical research. Malawi Medical Journal. 2012;24(3):69-71.

27. Nakku JE, Okello ES, Kizza D, Honikman S, Ssebun- nya J, Ndyanabangi S, et al. Perinatal mental health care in a rural African district, Uganda: a qualitative study of barriers, facilitators and needs. BMC Health Services Research. 2016;16(1):295. doi: 10.1186/s12913-016-1547-7.

28. Asiimwe C, Kyabayinze DJ, Kyalisiima Z, Nabakooza J, Bajabaite M, Counihan $\mathrm{H}$, et al. Early experiences on the feasibility, acceptability, and use of malaria rapid diagnostic tests at peripheral health centres in Uganda-insights into some barriers and facilitators. Implementation Science. 2012;7(1):5. doi: 10.1186/1748-5908-7-5.

29. Ahumuza SE, Rujumba J, Nkoyooyo A, Byaruhanga $\mathrm{R}$, Wanyenze RK. Challenges encountered in providing integrated HIV, antenatal and postnatal care services: a case study of Katakwi and Mubende districts in Uganda. Reproductive Health. 2016;13(1):41. doi: 10.1186/s12978016-0162-8.

30. Mugisha J, Ssebunnya J, Kigozi FN. Towards understanding governance issues in integration of mental health into primary health care in Uganda. International Journal of Mental Health Systems. 2016;10(1):1. doi: 10.1186/s13033016-0057-7.

31. Ssebunnya J, Kigozi F, Ndyanabangi S. Developing a national mental health policy: A case study from Uganda. PLoS Medicine. 2012;9(10):e1001319. doi: 10.1371/journal.pmed.1001319. 